This is an electronic reprint of the original article. This reprint may differ from the original in pagination and typographic detail.

Author(s): Soini, Anne; Watt, Anthony; Tammelin, Tuija; Soini, Markus; Sääkslahti, Arja; Poskiparta, Marita

Title: $\quad$ Comparing the physical activity patterns of 3-year-old Finnish and Australian children during childcare and homecare days

Year: $\quad 2014$

Version:

Please cite the original version:

Soini, A., Watt, A., Tammelin, T., Soini, M., Sääkslahti, A., \& Poskiparta, M. (2014). Comparing the physical activity patterns of 3-year-old Finnish and Australian children during childcare and homecare days. Baltic Journal of Health and Physical Activity, 6(3), 171-182. https://doi.org/10.2478/bjha-2014-0015

All material supplied via JYX is protected by copyright and other intellectual property rights, and duplication or sale of all or part of any of the repository collections is not permitted, except that material may be duplicated by you for your research use or educational purposes in electronic or print form. You must obtain permission for any other use. Electronic or print copies may not be offered, whether for sale or otherwise to anyone who is not an authorised user. 
Authors' Contribution:

A - Study Design

B - Data Collection

C - Statistical Analysis

D - Data Interpretation

E - Manuscript Preparation

$F$ - Literature Search

$\mathrm{G}$ - Funds Collection

\title{
Comparing the physical activity patterns of 3- year-old Finnish and Australian children during childcare and homecare Days
}

\author{
Anne Soini ${ }^{1 \text { ABCDEF }}$, Anthony Watt ${ }^{2}$ ABCDEF, Tuija Tammelin 3 ADEF, \\ Markus Soini ${ }^{4 \text { ABDE }}$, Arja Sääkslahti ${ }^{4 \text { ADEF }}$, Marita Poskiparta 5 ADEG \\ ${ }^{1}$ University of Jyväskylä, Department of Education, Early Childhood Education, \\ Jyväskylä, Finland \\ ${ }^{2}$ Victoria University, College of Education, Melbourne, Australia \\ ${ }^{3}$ LIKES - Research Center for Sport and Health Sciences, Jyväskylä, Finland \\ ${ }^{4}$ University of Jyväskylä, Department of Sport Sciences, Jyväskylä, Finland \\ ${ }^{5}$ University of Jyväskylä, Department of Health Sciences, Jyväskylä, Finland
}

Key words: accelerometer, physical activity, country comparison, preschool children

Material/Methods: ActiGraph GT3X accelerometers were used to monitor 121 (80 Finnish, 41 Australian)

Abstract

Background: Limited previous research has contrasted physical activity (PA) patterns in preschool children across different hourly patterns or segments of day, or adopted similar methodologies to compare the PA behaviors of children from different countries. The purpose of this study was to examine how the PA levels and patterns differed between 3year-olds within and between childcare and homecare days in Finland and Australia. children's $P A$ for five consecutive days.

Results: No significant country differences were observed in children's daily total PA (light-tovigorous PA [LMVPA]), except that during childcare days Finnish children spent more time in light PA compared to Australian children. During childcare attendance hours children engaged in moderate-to-vigorous PA (MVPA) for an average of 48 minutes $(S D=24)$ covering $54 \%$ of their daily MVPA in Finland, and for 53 minutes $(S D=34)$ covering $64 \%$ of their daily MVPA in Australia. Variation in children's hour-by-hour PA was more pronounced during childcare days than homecare days.

Conclusions: Despite the variations based on cultural practices, no major differences were observed in children's daily total PA between the countries. However, these findings provide a better understanding of 3-year-olds' PA behavior patterns and will serve as valuable evidence for the development of PA promotion in preschool children in both Finland and in Australia.

Word count: 4,631

Tables: 3

Received: May 2014

Figures: 2

Accepted: June 2014

References: 43

Published: October 2014

Corresponding author:

Anne Soini, M.Sc.

University of Jyväskylä, Department of Education, Early Childhood Education

P.O. Box 35

Fl-40014 University of Jyväskylä, Finland

Phone: +358 408054801

E-mail: anne.soini@jyu.fi 


\section{Introduction}

Lifestyle habits such as physical activity (PA) and sedentary behavior (SB) are established during the early years of childhood [1,2]. Engaging in efficacious PA as a child can serve as a foundation for a physically active adult lifestyle [3, 4]; however, SB seems to constitute an even stronger influence on later lifestyle $[5,6]$. Moreover, decreasing SB and increasing children's PA is a worldwide health priority $[6,7]$.

The common preconception among adults is that preschool children (3-to-5-years old) are naturally very active; however, studies of objectively measured PA and SB undertaken with this age group have drawn attention to the fact that levels of PA are typically low and of SB high [8,9]. It is possible that childcare settings may act as barriers to PA [9]. Secondly, the habits associated with SB such as TV viewing are formulated and maintained within Western populations in early childhood $[5,6]$. Low levels of PA and high levels of SB are related to health-risk behaviors such as increased consumption of unhealthy foods [8] and abnormal weight gain [4]. Despite the benefits of PA to young children's physical, social and psychological development [1], previous studies have indicated that preschoolers do not achieve the standards proposed in global guidelines for daily PA $[9,10]$.

According to the Organization for Economic Co-operation and Development (OECD) Family database [11], $69 \%$ in Europe, $36 \%$ in US and $12 \%$ of 3 -year-old children in Australia attend childcare or early education services. Because children spend considerable time at childcare, this setting can make an important contribution to the welfare and health of young children via an influence on their levels of PA behavior [12, 13, 14]. For instance, Finn et al. [12] concluded that the childcare center was the strongest predictor of activity levels among children attending childcare, with more than $50 \%$ of the daily PA performed during childcare hours. Results of a review by Hinkley et al. [15] showed that boys were more active than girls, that children with active parents tended to be more active, and that children who spent more time outdoors were more active than children who spent less time outdoors. Similarly, a recent comparison study involving Swedish and US preschool children demonstrated that PA was significantly higher outdoors than indoors during preschool time for both countries, and that time spent outdoors seemed to be a supportive aspect of objectively measured MVPA for preschool children [16].

The assessment of young children's PA is challenging, primarily because their behavior is intermittent and sporadic; therefore, objective measures such as accelerometers are recommended for use to detect these short spurts and to determine frequencies, intensities and duration of PA $[8,17,18]$. Although, accelerometers have become one of the most widely used methods for measuring PA and SB in free-living preschool children [17, 18, 19, 20] only limited research exists that considered PA variability in preschool children across different segments of day or PA patterns hour-by-hour [21, 22]. Furthermore, the number of studies that have adopted similar designs and methodologies to compare PA behaviors of children from different countries in childcare and home settings is minimal. The aim of this study, therefore, was to investigate variations in the daily childcare and homecare PA levels and patterns of Finnish and Australian 3year-olds.

\section{Material and Methods}

Participants in Finland. Finnish participants were recruited from Central Finland, in a large regional city. A total of 14 childcare centers volunteered to be involved in the study. All families of the 3-year-old children attending the participating childcare centers were invited to participate. A total of 96 (48 boys and 48 girls) children participated in the data collection from August to October (Autumn).

Participants in Australia. Australian participants were recruited from the inner and outer western urban regions of a major metropolitan city. All families of 3-year-old children attending the 13 childcare centers that agreed to participate were invited to be involved in the project. Parent completion of consent forms resulted in the involvement of 64 (33 boys and 31 girls) children with in the data collection from March to August (Autumn to Winter). 
The minimum valid PA requirement for the use of participant accelerometer daily data was at least 450 minutes of monitored PA per day (from 7 a.m. to 9 p.m.) for at least one childcare day and one homecare day as recommended by Cliff et al. (25). From the total sample, 16 children $(17 \%)$ in Finland and 23 children $(36 \%)$ in Australia were excluded from further analyses because children did not satisfy the minimum wear time criteria. Complete PA data were obtained for 80 ( $53 \%$ boys) Finnish children and 41 (44\% boys) Australian children.

$P A$ assessment and data reduction. Daily PA was objectively quantified with the ActiGraph GT3X (ActiGraph, LLC, Pensacola, FL, US). For this study, children were requested to wear an accelerometer for five consecutive days (from Wednesday to Sunday). The devices were initialized to record data over 5-s intervals (epochs) as recommended for children of this age [17]. The separate count cut points for preschool-aged children established by Pate et al. [23] were adapted for this study to assess the amounts of time the children spent at the different intensity levels and to determine how many of children achieve the PA recommendations for preschoolers [24, 25, 26, 27 , $28,29]$. The following cut points determined by counts per minute (cpm) were used: sedentary (0-149 cpm), light (150-1679 cpm) and moderate-to-vigorous intensity physical activity (MVPA) $(\geq 1680 \mathrm{cpm}$ ) (23). Recently, cut points of $<100 \mathrm{cpm}$ and $1680 \mathrm{cpm}$ for classifying SB and MVPA, respectively, are recommended [30].

All data were checked for normality before statistical analysis. Periods of non-wear time (defined as 10 consecutive minutes of ' 0 ' counts) and an upper range of biological plausibility (defined as no more than $15,000 \mathrm{cpm}$ ) were removed from the data [17]. The days during which participants did not achieve the minimal wearing time were considered as a noncompliant day and not used in the analyses. PA levels in cpm were derived as the main PA outcome. Daily PA levels (cpm/day), PA levels per hour (cpm/hour) and time spent at different PA intensity levels (i.e., sedentary, light PA and MVPA) in minutes/hour were calculated to assess both within- and between-day variability. In both childcare and homecare day hours between 7 a.m. and 9 p.m. were included to analyze within-day variability. The data reduction was done with using ActiLife version 6.5.2.

Accelerometers were worn for an average of $4.5(S D=.65)$ days, $634(S D=55)$ minutes/childcare days and $623(S D=66)$ minutes/homecare days in Finland. In Australia accelerometers were worn for an average of $4.3(S D=.91)$ days, $592(S D=65)$ minutes/childcare day and $579(S D=49)$ minutes/homecare day. No differences in mean monitor wearing days $(p=.128)$ were observed between Finnish and Australian children; however, Finnish children had a significantly higher mean wearing minutes/day compared to Australian children of 42 minutes for childcare days $(p=.001)$ and of 44 minutes for homecare days $(p=.001)$.

$P A$ monitoring procedures. The parents and children were issued with an accelerometer on the first morning of their involvement in the research. All children, together with their parents and childcare teachers, were instructed how to wear the accelerometer using an adjustable elastic belt over children's right hip for as long as possible during all waking hours, and that to remove it only for water-based activities and when sleeping. Parents, childcare teachers and center managers were also provided written information about the correct procedures and proper accelerometer use.

Parents were asked to record childcare attendance times. Additionally, parents were asked to report any abnormalities in daily routines, for example, long periods spent sitting (e.g., in a car), swimming, bathing and if the child was ill during the measurement period. Receptivity to wearing the instrument was rated by the parent on a five-point scale (from very pleasant to very unpleasant). According to parents' reports of their children's receptivity to wearing the accelerometer, $95 \%$ of Finnish and $89 \%$ of Australian children reported experience as "pleasant" or "very pleasant". Only $1 \%$ of the Finnish and $11 \%$ of Australian children reported the experience as "unpleasant" and none as "very unpleasant".

Background information in Finland. Typically Finnish childcare centers are community based and catered care for less than a hundred children. The typical age cohort that 3-year-old children are involved with at childcare are the 3-5-year-olds group. For 3-year-olds, childcare settings should provide one certified teacher per seven children [31]. Finnish childcare centers', involved in this study, typical daily timetable is scheduled by meal times (8 till 8.30 a.m. breakfast; 11 till 11.30 a.m. lunch; 2 till 2.30 p.m. snack) and rest (12 till 2 p.m.), morning (10 till 11 a.m.) and afternoon (3 
till 5 p.m.) outdoor recess. After breakfast there are teacher-lead classroom activities. These sessions can include pre-academic activities, music, handicrafts, or physical education (P.E.). In this study during the data collection periods, the participants attended childcare settings for an average of $7.7(S D=.84)$ hours/day from 8 a.m. to 3.30 p.m. The mean outdoor temperature during Finnish data collection was average $9^{\circ} \mathrm{C}$ (range: $16^{\circ} \mathrm{C}--^{\circ} \mathrm{C}$ ) [32].

Background information in Australia. In contrast to the Finnish childcare system, Australian childcare centers are managed by the government, community, and private organizations. The numbers of children in attendance varies considerably depending on the funding and resources available to the centers. Centers operate on a half or full-day fee charged to parents for the care of their child. In the recruited childcare centers a typical daily schedule involves the following general routine: breakfast at 8 a.m., morning tea at 9.30 a.m., lunch at 11.30 a.m., sleep time or quiet activities at 12 p.m., afternoon tea at 3 p.m. and a late afternoon meal/snack time at 5.30 p.m. Between the meals children are allowed to play indoors or outdoors depending on the weather. During the day there might also be structured group time for 3-to-5-year-olds. The Australian participants attended childcare settings for an average of $8.1(S D=1.95)$ hours/day from 8.30 a.m. to 4.30 p.m. The mean outdoor temperature during Australian data collection was $12^{\circ} \mathrm{C}$ (range: $\left.22^{\circ} \mathrm{C}-6^{\circ} \mathrm{C}\right)[32]$.

In Finland body weight and height were measured by researchers at the time of PA data collection. In Australia, parents or the guardians were asked to provide children's body weight and height information. Body mass index (BMI: $\mathrm{kg} / \mathrm{m}^{2}$ ) was calculated for each child (see Table 1). In Finland, the ethics committee of the local University, and the Social Affairs and Health officer in the city approved the study. The affiliate Australian University and Department of Education and Early Childhood provided ethical approval in Australia.

Statistical analysis. The data were analyzed using SPSS for Windows (version 20.0). Descriptive statistics were used to summarize the study sample in relation to the main variables. Means and standard deviations $(S D)$ were calculated for daily total PA expressed as $\mathrm{cpm}$, and time spent (percentages/day) at different intensity levels (sedentary, light PA, and MVPA) to show the extent of activity behavior. To compare PA levels on childcare and homecare days, paired-samples $t$-tests were conducted. Gender differences in total PA and in engagement at different intensity levels were analyzed using independent-samples $t$-test. A repeated measure MANOVA was used to compare differences in daily PA between childcare and home days for gender, country, and hour of the day. Statistical significance was set at an alpha level of .05 for all analyses.

\section{Results}

Children's daily total $P A$. Children's total PA was $M=730 \mathrm{cpm}, S D=139$ (Finland $M=739$ $\mathrm{cpm}, S D=143$ and Australia $M=713 \mathrm{cpm}, S D=132)$. No significant differences were observed in mean daily $\mathrm{cpm}$ between childcare days $(M=715 \mathrm{cpm}, S D=149)$ and homecare days $(M=745$ $\mathrm{cpm}, S D=192 ; t=-1.66, p=.101)$. During childcare days boys' $(M=748 \mathrm{cpm}, S D=152)$ activity levels were higher than girls' $(M=683 \mathrm{cpm}, S D=141)(F=.702, t=2.45, p=.016)$, but no gender differences were observed during homecare days $(p=.158)$. No country variations were recorded in activity intensities during childcare or homecare days, except during childcare days Finnish children spent more time (average 20 minutes) in light PA than Australian children $(p=.027)$. Descriptive characteristics and total PA of the participants by country are shown in Table 1. 
Table 1. Descriptive characteristics and total physical activity of the participants by country

\begin{tabular}{|c|c|c|c|c|c|c|}
\hline & & \multicolumn{2}{|c|}{$\begin{array}{c}\text { Finland } \\
(N=80,53 \% \text { boys })\end{array}$} & \multicolumn{2}{|c|}{$\begin{array}{c}\text { Australia } \\
(N=41,44 \% \text { boys })\end{array}$} & \multirow[b]{2}{*}{$p$-value } \\
\hline & & Mean & $S D$ & Mean & $S D$ & \\
\hline Age (yrs) & & 3.2 & 0.3 & 3.4 & 0.2 & $<.001$ \\
\hline Height (cm) & & 98.1 & 4.5 & 101.5 & 3.3 & .006 \\
\hline Weight (kg) & & 15.7 & 1.7 & 16.3 & 2.1 & .114 \\
\hline BMI (kg/cm²) & & 16.2 & 1.1 & 16.3 & 1.2 & .773 \\
\hline \multicolumn{7}{|c|}{ PA during childcare day } \\
\hline & $\mathrm{cpm}$ & 728 & 136 & 687 & 170 & .157 \\
\hline & Sedentary & \multicolumn{2}{|c|}{$55 \%$} & \multicolumn{2}{|c|}{$57 \%$} & .084 \\
\hline & Light PA & \multicolumn{2}{|c|}{$31 \%$} & \multicolumn{2}{|c|}{$29 \%$} & .027 \\
\hline & MVPA & \multicolumn{2}{|c|}{$14 \%$} & \multicolumn{2}{|c|}{$14 \%$} & .539 \\
\hline \multicolumn{7}{|c|}{ PA during homecare day } \\
\hline & cpm & 749 & 212 & 737 & 145 & .743 \\
\hline & Sedentary & \multicolumn{2}{|c|}{$55 \%$} & \multicolumn{2}{|c|}{$55 \%$} & .676 \\
\hline & Light PA & \multicolumn{2}{|c|}{$31 \%$} & \multicolumn{2}{|c|}{$30 \%$} & .661 \\
\hline & MVPA & \multicolumn{2}{|c|}{$15 \%$} & \multicolumn{2}{|c|}{$15 \%$} & .826 \\
\hline
\end{tabular}

Note: BMI: Body mass index; cpm: counts per minute; cut points for counts/60s: sedentary 0-149, light PA 150-1679;

MVPA: moderate-to-vigorous intensity $\geq 1680 \mathrm{cpm}^{9}$.

During childcare days all Finnish and $95 \%$ of Australian children engaged in LMVPA for 180 minutes or more and $96 \%$ of Finnish and $83 \%$ of Australian children engaged in MVPA for 60 minutes or more. Only $10 \%$ of Finnish and $15 \%$ of Australian engaged in MVPA for 120 minutes or more. During homecare days, $98 \%$ of Finnish and $95 \%$ of Australian children engaged in LMVPA for 180 minutes or more, $89 \%$ of Finnish and $90 \%$ of Australian children engaged in MVPA for 60 minutes or more and $14 \%$ of Finnish and $5 \%$ of Australian engaged in MVPA for 120 minutes or more.

PA patterns during childcare days. A significant main effect of hour $(F=57.24, p<.001)$, and interaction effect of hour-country $(F=14.52, p<.001)$ revealed that PA levels per hour and country varied across a childcare day (Figure 1 ). Between-subjects analysis indicated that PA varied by country $(F=4.87, p=.029)$ and gender $(F=5.65, p=.019)$ during a childcare day. During childcare attendance hours, two significant increases in activity levels were monitored in both countries: between 10 and 11 a.m. and between 3 and 4 p.m. in Finland, and between 10 and 11 a.m. and between 4 and 5 p.m. in Australia. One major decline in PA levels was recorded during the resting times (12 till 2 p.m. in Finland; 1 till 2 p.m. in Australia). In Finland, one increase in activity levels was recorded after childcare hours, between 6 and 7 p.m. In Australia, during post childcare attendance hours children's PA levels decreased (See Figure 1). Childcare days' average minutes/hour in different activity intensities (sedentary, light PA, MVPA) are shown in Table 2. Children engaged in MVPA for an average of 48 minutes ( $S D=24 ; 54 \%$ of daily MVPA), in LMVPA for 147 minutes $(S D=55 ; 53 \%$ of daily LMVPA) in Finland; and in MVPA for 53 minutes ( $S D=34 ; 64 \%$ of daily MVPA) and in LMVPA for 163 minutes (SD $=79 ; 64 \%$ of daily LMVPA) in Australia during their childcare attendance hours.

$P A$ patterns during homecare days. A significant main effect of hour $(F=38.30, p<.001)$, and interaction effect for hour-country $(F=2.80, p=.002)$ indicated that PA levels varied by hour and country during a homecare day (Figure 2). Between-subjects analysis showed no variation be- 
tween variables across a homecare day. In Finland, PA levels increased between 10 and 12 p.m., 3 and 5 p.m., and these activity levels remained the same until 8 p.m. A small decline in activity levels was observed between 1 and 2 p.m. In Australia, children's PA levels increased at 9 a.m. and remained the same level until 4 p.m., when the next peak was recorded. After 5 p.m. children's PA levels were decreasing respectively. Homecare days' average minutes/hour in different activity intensities (sedentary, light PA, MVPA) are shown in Table 3.

Table 2. Average minutes/hour during childcare days in different activity intensities (sedentary, light PA and MVPA)

\begin{tabular}{|c|c|c|c|c|c|c|c|c|c|c|c|c|}
\hline \multirow{3}{*}{ Time } & \multicolumn{6}{|c|}{ Finland $(N=80)$} & \multicolumn{6}{|c|}{ Australia $(N=41)$} \\
\hline & \multicolumn{2}{|c|}{ Sedentary } & \multicolumn{2}{|c|}{ Light PA } & \multicolumn{2}{|c|}{ MVPA } & \multicolumn{2}{|c|}{ Sedentary } & \multicolumn{2}{|c|}{ Light PA } & \multicolumn{2}{|c|}{ MVPA } \\
\hline & Mean & $S D$ & Mean & $S D$ & Mean & $S D$ & Mean & $S D$ & Mean & $S D$ & Mean & $S D$ \\
\hline 7 a.m. & 47.5 & 7.9 & 8.5 & 4.6 & 3.3 & 2.1 & 13.5 & 10.9 & 4.6 & 4.0 & 1.8 & 1.7 \\
\hline 8 a.m. & 40.4 & 7.1 & 13.2 & 3.9 & 6.3 & 4.0 & 26.0 & 11.7 & 11.3 & 5.7 & 5.0 & 3.5 \\
\hline 9 a.m. & 29.7 & 7.3 & 19.6 & 4.4 & 10.7 & 4.4 & 33.5 & 9.2 & 14.9 & 4.5 & 6.0 & 3.3 \\
\hline 10 a.m. & 25.2 & 6.9 & 22.2 & 4.3 & 12.6 & 5.0 & 29.2 & 8.1 & 19.8 & 4.3 & 10.1 & 5.4 \\
\hline 11 a.m. & 43.9 & 6.8 & 10.9 & 3.6 & 4.2 & 2.2 & 34.4 & 7.0 & 16.1 & 4.3 & 7.8 & 4.4 \\
\hline 12 p.m. & 52.3 & 13.0 & 3.9 & 5.4 & 1.2 & 1.9 & 21.3 & 14.1 & 11.6 & 7.3 & 5.8 & 4.6 \\
\hline 1 p.m. & 52.2 & 11.5 & 4.0 & 3.8 & 1.5 & 2.0 & 12.4 & 14.0 & 7.4 & 8.3 & 3.5 & 4.2 \\
\hline 2 p.m. & 38.8 & 5.8 & 14.8 & 3.6 & 6.3 & 2.8 & 22.5 & 13.5 & 9.2 & 6.0 & 3.9 & 3.3 \\
\hline 3 p.m. & 29.3 & 6.7 & 20.3 & 4.1 & 10.4 & 4.1 & 30.8 & 9.2 & 15.6 & 4.8 & 8.5 & 4.6 \\
\hline 4 p.m. & 35.0 & 6.1 & 17.4 & 4.0 & 7.5 & 2.9 & 26.9 & 7.0 & 19.7 & 5.2 & 10.1 & 4.5 \\
\hline 5 p.m. & 39.6 & 7.5 & 13.6 & 4.2 & 6.2 & 3.4 & 29.5 & 8.6 & 15.7 & 4.4 & 7.5 & 4.8 \\
\hline 6 p.m. & 34.8 & 7.1 & 17.2 & 4.7 & 8.0 & 3.4 & 24.3 & 10.9 & 12.6 & 6.1 & 5.7 & 3.9 \\
\hline 7 p.m. & 38.3 & 7.9 & 14.6 & 5.2 & 6.8 & 3.5 & 18.2 & 11.0 & 9.0 & 5.9 & 5.0 & 4.8 \\
\hline 8 p.m. & 46.4 & 10.4 & 8.5 & 6.2 & 4.1 & 3.2 & 7.1 & 9.4 & 4.2 & 6.4 & 2.2 & 3.9 \\
\hline
\end{tabular}

Note. MVPA: Moderate-to-vigorous physical activity; SD: standard deviations

Table 3. Average minutes/hour during homecare days in different activity intensities (sedentary, light PA, MVPA)

\begin{tabular}{|c|c|c|c|c|c|c|c|c|c|c|c|c|}
\hline \multirow{3}{*}{ Time } & \multicolumn{6}{|c|}{ Finland $(N=80)$} & \multicolumn{6}{|c|}{ Australia $(N=41)$} \\
\hline & \multicolumn{2}{|c|}{ Sedentary } & \multicolumn{2}{|c|}{ Light PA } & \multicolumn{2}{|c|}{ MVPA } & \multicolumn{2}{|c|}{ Sedentary } & \multicolumn{2}{|c|}{ Light PA } & \multicolumn{2}{|c|}{ MVPA } \\
\hline & Mean & $S D$ & Mean & $S D$ & Mean & $S D$ & Mean & $S D$ & Mean & $S D$ & Mean & $S D$ \\
\hline 7 a.m. & 51.8 & 13.2 & 3.8 & 4.5 & 1.5 & 1.9 & 8.6 & 10.6 & 3.6 & 4.7 & 1.5 & 2.0 \\
\hline 8 a.m. & 46.7 & 10.3 & 8.2 & 5.4 & 3.3 & 2.6 & 18.4 & 11.5 & 9.2 & 6.6 & 4.2 & 3.3 \\
\hline 9 a.m. & 39.0 & 9.9 & 14.4 & 6.3 & 5.9 & 3.3 & 24.4 & 8.5 & 13.8 & 6.1 & 7.0 & 4.7 \\
\hline 10 a.m. & 34.1 & 8.6 & 17.5 & 5.0 & 8.2 & 4.7 & 26.2 & 9.3 & 14.6 & 5.3 & 7.1 & 3.7 \\
\hline 11 a.m. & 34.5 & 7.8 & 17.5 & 5.2 & 8.0 & 4.4 & 28.6 & 5.3 & 16.4 & 4.7 & 7.5 & 3.7 \\
\hline 12 p.m. & 38.1 & 10.0 & 14.6 & 6.6 & 6.9 & 4.4 & 28.8 & 6.5 & 16.7 & 4.4 & 7.7 & 3.7 \\
\hline 1 p.m. & 42.1 & 10.7 & 12.3 & 6.9 & 5.4 & 4.4 & 28.5 & 7.3 & 15.3 & 5.2 & 6.8 & 3.7 \\
\hline 2 p.m. & 39.6 & 10.6 & 14.0 & 6.8 & 6.4 & 4.7 & 26.5 & 9.6 & 14.2 & 6.0 & 6.7 & 4.1 \\
\hline 3 p.m. & 35.2 & 10.5 & 16.3 & 6.0 & 8.5 & 6.0 & 24.1 & 9.0 & 15.2 & 6.2 & 7.3 & 4.3 \\
\hline 4 p.m. & 34.8 & 9.3 & 16.6 & 5.4 & 8.7 & 5.2 & 23.1 & 8.1 & 15.7 & 5.6 & 8.8 & 5.0 \\
\hline 5 p.m. & 36.5 & 8.7 & 15.4 & 5.3 & 7.7 & 4.3 & 25.7 & 7.8 & 14.2 & 5.1 & 7.3 & 4.2 \\
\hline 6 p.m. & 37.3 & 9.7 & 15.1 & 6.2 & 7.6 & 4.3 & 26.4 & 8.7 & 12.3 & 5.1 & 5.1 & 2.6 \\
\hline 7 p.m. & 39.4 & 10.6 & 13.0 & 6.6 & 7.5 & 4.9 & 17.1 & 10.4 & 8.9 & 6.8 & 4.5 & 3.0 \\
\hline 8 p.m. & 45.6 & 12.8 & 8.6 & 6.9 & 4.6 & 4.7 & 7.6 & 8.6 & 4.4 & 5.9 & 2.2 & 3.1 \\
\hline
\end{tabular}




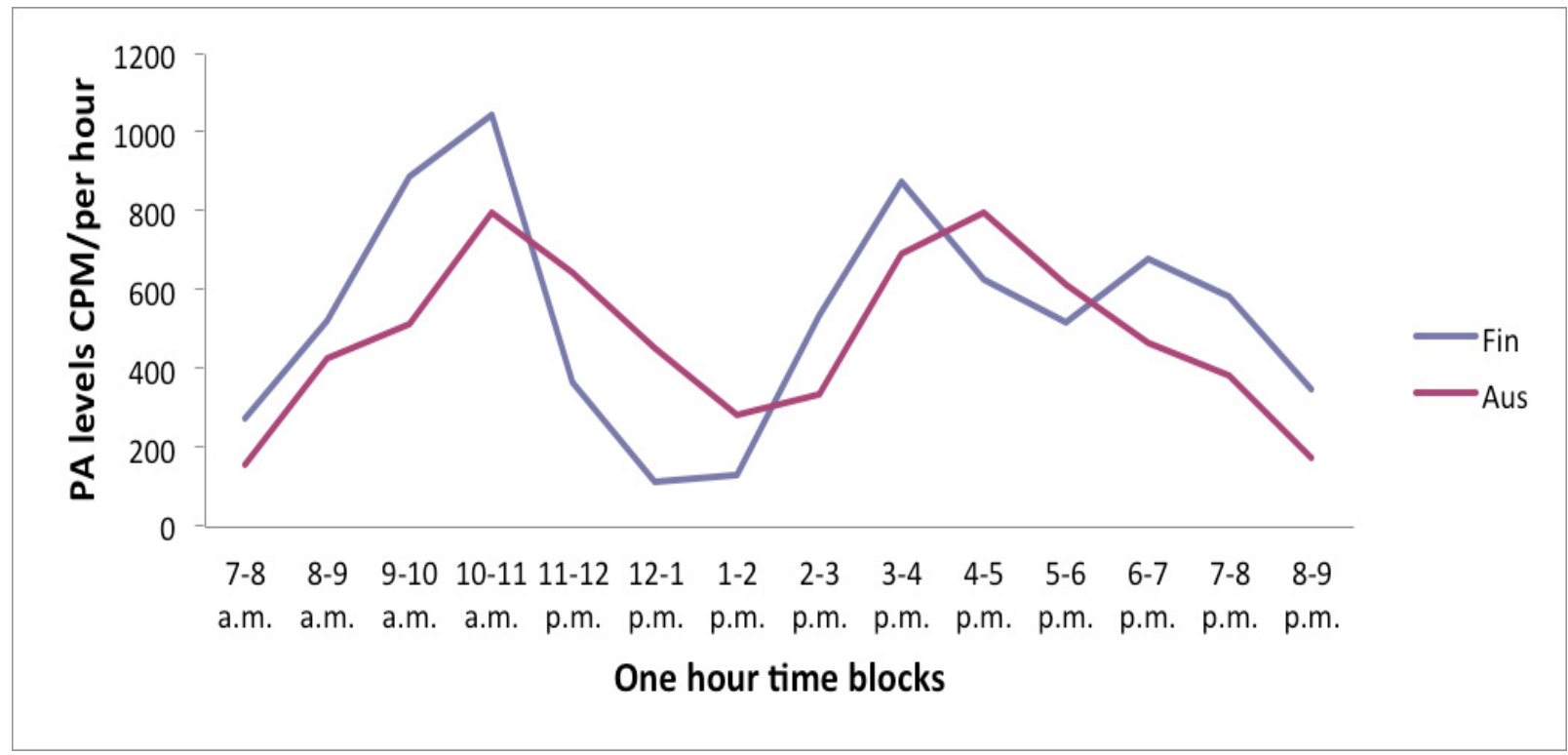

Fig. 1. Physical activity levels (cpm/hour) during childcare days

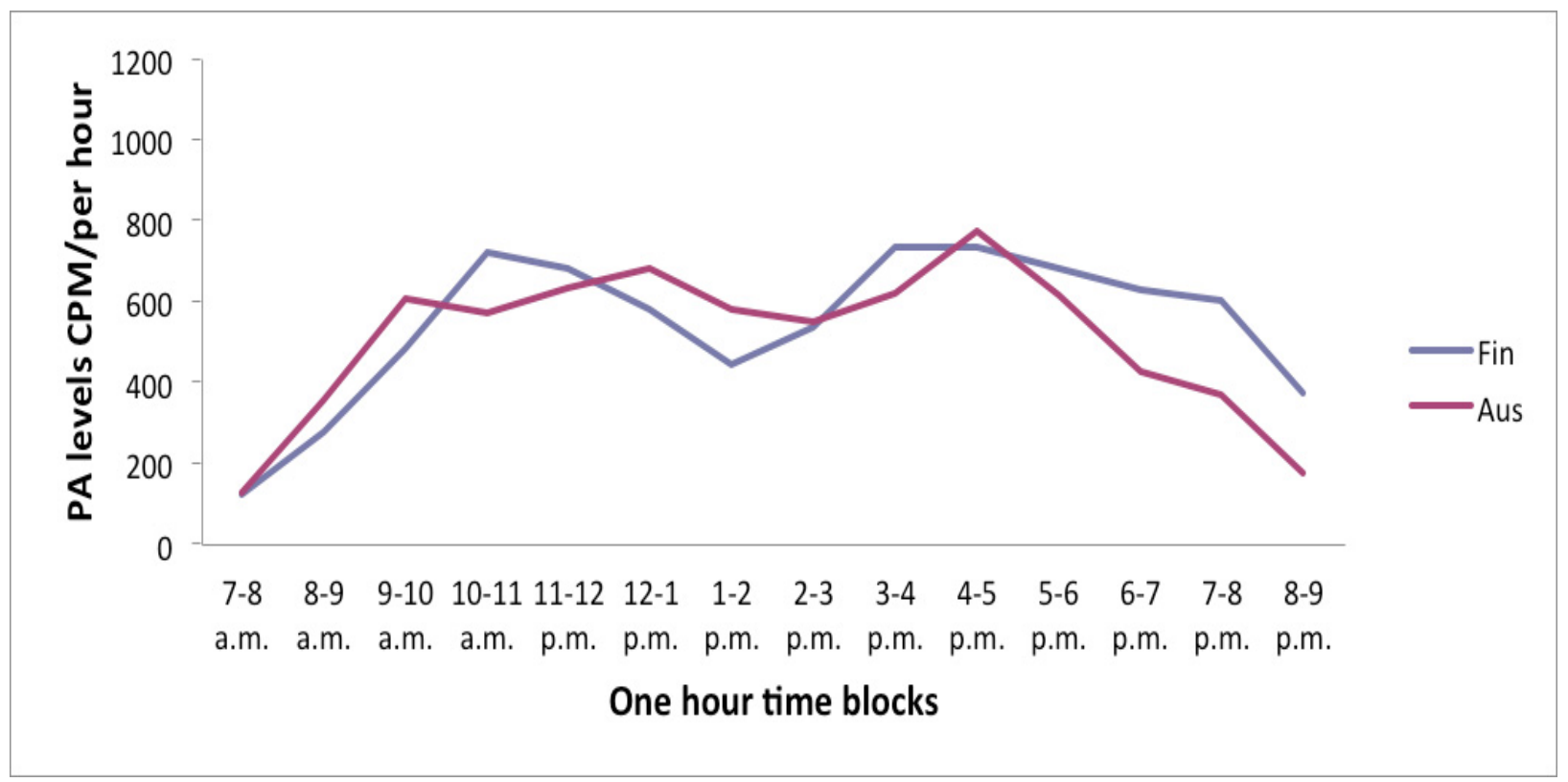

Fig. 2. Physical activity levels (cpm/hour) during homecare days

\section{Discussion}

The purpose of this study was to determine 3-year-old children's PA levels and to compare how these levels varied within and between childcare days and homecare days and differed between Finnish and Australian children. No significant country differences were found in children's daily total PA, when PA was expressed as cpm. However, during childcare days Finnish children spent more time in light PA compared to Australian children. During childcare attendance hours children engaged in MVPA for $54 \%$ of their daily MVPA in Finland, and $64 \%$ of their daily MVPA in Australia. Children's PA levels' variation, hour-by-hour, was more pronounced during childcare days than homecare days, especially in Finland. Most of the children engaged in three hours or more of daily LMVPA [24, 25, 26, 27], or 60 minutes or more of MVPA, as widely recommended for preschoolers [29]. 
The mean total PA scores for the children in the present study appeared to be higher than those reported previously in similar studies in different countries [22, 33, 34, 35, 36]. For example, in Scotland Jackson et al. [35] found total activity counts of $669 \mathrm{cpm}$ and Reilly et al. [36] 692 for 3year-olds for compared to the mean of $730 \mathrm{cpm}$ found in this study. Earlier preschool PA research has shown boys to be more active than girls [12, 15, 35, 37]. Children tend to be less active when more staff members are present or involved with children's play [38, 39]. Girls in particular prefer to stay close to their teachers, thus, decreasing activity levels when teachers are present [40]. Similarly, the current study also found gender differences in PA intensity levels in childcare days, but not during homecare days.

Strong et al. [4] reported that preschools should provide opportunities for children to accumulate 60 minutes and more of MVPA each day. Many studies, however, have typically indicated that PA levels are very low among preschool children during their time in childcare settings $[9,13]$. The current results tend to support this pattern whereby both samples of children did not meet the recommended minimum of 60 minutes of MVPA during childcare hours [4]. However, this study indicated that during childcare hours children engaged in $56 \%$ of their daily MVPA and $53 \%$ of their daily LMVPA in Finland; and in 64\% of their daily MVPA and $64 \%$ of their daily LMVPA in Australia. This finding supports the earlier research of Finn et al. [12].

Children's PA patterns during childcare days. Despite no stated differences in children's childcare days' total PA between countries, Finnish children engaged more in light PA compared to Australian 3-year-olds. A Belgian study previously reported significant increases in children's objectively measured PA intensity during preschool recess and in times of unstructured free plays that were taken as an opportunity to be physically active [22]. Similarly, Finnish children's intensity levels peaked twice during childcare attending hours, at 10 a.m. and 3 p.m., reaching the highest MVPA levels during the day. This may be explained by the specific practices within Finnish childcare whereby settings generally only offer children an opportunity to engage in outdoor activities twice a day, in the mornings and afternoons.

In Finland, outdoor times are associated with unstructured and free play in the playground. Also, several previous studies have indicated that children who spend more time outdoors are more physically active [12, 15, 17, 37, 41]. Cardon et al. [40] have suggested that the provision of sufficient play space for recesses (e.g., splitting children into groups with different recess times), favoring shorter and more frequent recesses during preschool hours or encouraging supervisors to promote continued activity during outdoor play offer considerable potential for increasing activity levels in preschoolers. Increases in PA within the Australian sample were also found at 10 a.m. and at 4 p.m. It is probable that during those hours children have been outdoors; however, the childcare programs in Australia are less restrictive in relation allowing children to play in the outdoor play area throughout the day. Despite these opportunities to play outdoors, Australian children's PA levels were surprisingly low. Relative to Cardon et al.'s [40] findings, it could be expected that Australian children in this study should have reached higher levels of activity.

A noticeable decline in Finnish children's intensity levels were observed during midday hours, between 12 p.m. and 1 p.m. Finnish children are required to have a day sleep, or at least lie down for an average of 30 minutes. For the Australian sample, intensity levels decreased minimally between 1 p.m. and 2 p.m., possibly because the day sleep time was less formally implemented than in Finland. The typical childcare days in both countries were also characterized by essential daily living activities such as dressing, eating, engaging in self-care activities and structured classroombased activities (e.g., fine motor activities, pre-academic activities), which are shown in the current results as lower PA level behaviors. Integrating PA into an existing preschool curriculum is a potential strategy to enhance PA in preschoolers [42].

One notable difference between the countries was revealed in the children's typical childcare attendance times. Australian children attend childcare settings approximately 30 minutes more in comparison to Finnish children. However, in Finland, as is typical in the Nordic countries, children attend formal care full-time on five days, more than 30 hours per week, whereas, at the age of three children in Australia frequent childcare with substantial variation in attendance patterns (i.e., 1 day through to 5 days per week; less than 20 hours per week) [11]. 
Outside of childcare hours data revealed one increase (between 6 p.m. and 7 p.m.) in Finnish children's PA levels. This supports thinking that parents are taking their children to the park or children are participating in structured activities managed by sport clubs or private organizations (e.g., swim school). During this peak however, children's MVPA levels were lower than during the childcare hours. Congruent with results of the study of Verbestel et al. [22], the Australian data confirmed that after childcare hours were associated with reduced activity levels. Parents may assume that their child is getting enough PA during the childcare day, which could limit encouragement of the child to be physically active or to play outdoors after childcare hours. It is possible that the present sample of children is engaged in SB such as TV viewing or using computers, similarly observed in Belgium [40]. While SB tracks more consistently than PA; therefore, reducing children's $\mathrm{SB}$, especially TV viewing, and promoting their PA during the early childhood period can bring sustained benefits that carry over into childhood [6].

Children's PA patterns during homecare days. Homecare hourly patterns of PA determined in the current study are similar to the findings of Verbestel et al. [22], whereby, two increases in children's activity levels on homecare days (i.e., Finnish) were recorded between 10 a.m. and 11 a.m. and 3 p.m. and 6 p.m. Additionally, Australian children's PA intensity levels were higher during hours between 11 a.m. and 12 p.m. These minor activity peaks were recorded slightly later than on childcare days. Children probably wake up later during homecare days. Finnish children's afternoon increase in PA supports thinking that families are active in their home environment. No major increases in Australian children's PA during homecare serves as evidence supporting that children and their parents should be encouraged to spend more time playing outdoors or utilizing PA suitable settings. In general, activity patterns during homecare days were much less flattened and structured than during childcare days. Support for the current results is also found from Van Cauwenberghe et al.'s [21] report that hour-by-hour patterns of SB and MVPA were less variable during weekend days than during weekdays.

At the age of three, children may often spend weekdays at homecare, especially in Australia, and for this reason the study was designed to compare childcare days to homecare days instead weekdays to weekend days. The descriptive results revealed that no significant differences in intensity levels or total PA were found between childcare days and homecare days, thus, constituting findings consistent with earlier studies [22, 35]. It is possible that the current sample of families' essential daily living activities do not differ from childcare settings' structured programs. In contrast, Cardon and De Bourdeaudhuij [33] reported higher levels of sedentary behavior on weekdays compared to weekend days, although MVPA was as low during the weekend days as during the weekdays. Furthermore, Van Cauwenberghe et al. [21] reported that preschoolers were less sedentary and engaged in more MVPA across the weekend days compared to weekdays, and therefore, weekdays offer the greatest opportunity to change SB and MVPA.

$P A$ recommendations for preschool children. According to trends detailed in a review of the physical activity levels of preschool-aged children presented by Tucker [10], only $54 \%$ of participants throughout the studies achieved the minimum of 60 minutes of PA daily. In the current study, almost all of Finnish children and the large part of Australian children fulfilled the requirement of at least 60 minutes of MVPA daily. Additionally, although most children met the recommendations of three hours of daily LMVPA [24, 25, 26, 27], only small number of the Finnish or Australian children achieved the Recommendations for Physical Activity in Early Childhood Education [28] of at least 120 minutes of daily brisk PA (if defined as MVPA).

Strengths and limitations. Continuing debate exists in the literature as to the strengths and limitations of accelerometers. The choice of cut points significantly influences the amount of PA reported across different intensity levels; however, no consensus has been reached regarding which cut points are most appropriate for preschool-aged children [19]. Investigators in the field of PA need to resolve the issue of which accelerometer cut points are the most appropriate [19] and continue to focus on standardizing methods for the collection, cleaning, analyzing and reporting of accelerometer data [43]. Nevertheless, it is acknowledged that accelerometer generated data remain relatively accurate and warrant continued support as a reliable methodology for measuring PA and SB in free-living preschool children [17, 18, 20,42]. 
A valuable quality of the present research is that PA levels were objectively measured using accelerometers in two countries. Children's PA was measured over five days that included childcare and home settings in each of total of 27 childcare centers, covering both weekdays and weekend days in Finland and Australia. However, in Australia measurement could have benefitted from the inclusion of data for the entire week as an option rather than a Wednesday to Friday 3day protocol to facilitate the attainment of more valid childcare days. Moreover, the children were co-operative and eager to take part in this study. Proxy reports by parents of their child's receptivity to wearing the accelerometer clearly indicated that it was a positive experience for the majority of the children.

\section{Conclusion}

Despite cultural variation in certain methodological characteristics (i.e., variations in attendance times, seasonal time periods) no major differences associated with country were observed in children's daily total PA. During childcare attendance hours children engaged in MVPA for more than half of their daily MVPA. Variation in children's hour-by-hour PA level was more pronounced during childcare days than homecare days. This study provides a useful contribution to facilitating improved understanding of preschoolers' PA behavior and the development of future PA interventions in contrasting international contexts such as Finland and Australia. Reducing SB and integrating increased levels of PA into childcare settings' daily living activities has the potential to enhance PA in preschoolers. The basic evidence generated in this research may make a partial contribution toward encouraging and stimulating parents to work towards an improved provision of opportunities for physical activities, such as visiting parks or playground areas after childcare hours and during homecare days. In future, complementing accelerometer data with contextual information could provide clearer perceptions of the type of settings and contexts children are engaging in higher levels of PA.

\section{Acknowledgements}

The authors would like to sincerely thank the children, parents and teachers in the childcare centers who gave their time to participate in this study.

\section{References}

1. Timmons BW, Naylor PJ, Pfeiffer KA. Physical activity for preschool children - how much and how? Appl Physiol Nutr Metab. 2007;32:122-134.

2. Ward DS, Vaughn A, McWilliams C, Hales D. Interventions for increasing physical activity at childcare. Med Sci Sports Exerc. 2010;42:526-534.

3. Singh AS, Mulder C, Twisk JWR, van Mechelen W, Chin A Paw MJM. Tracking of childhood overweight into adulthood: a systematic review of the literature. Obes rev. 2008;9:474-488.

4. Strong WB, Malina RM, Blimkie CR, Daniels SR, Dishman RK, Gutin B. Evidence based physical activity for school-age youth. J Pediatr. 2005;146:732-737.

5. Biddle SJH, Pearson N, Ross GM, Braithwaite R. Tracking of sedentary behaviours of young people: A systematic review. Prev Med. 2010;51:345-351.

6. Jones RA, Hinkley T, Okely AD, Salmon J. Tracking physical activity and sedentary behaviour in childhood. A systematic review. Am J Prev Med. 2013;44(6):651-658.

7. World Health Organization (WHO). Population-based approaches to childhood obesity prevention. 2012. Geneva, Switzerland.

8. Oliver M, Schofield GM, Kolt GS. Physical activity in preschoolers. Understanding prevalence and measurement issues. Sports Med. 2007;37:1045-1070.

9. Reilly JJ. Low levels of objectively measured physical activity in preschoolers in child care. Med Sci Sports Exerc. 2010;42:502-507.

10. Tucker P. The physical activity levels of preschool-aged children: A Systematic Review. Early Child Res Q. 2008;23:547-558.

11. OECD Family Database. [http://www.oecd.org/els/social/family/database] Published 2008. Updated June 2011. [Accessed June 2, 2012]

12. Finn KJ, Johannsen N, Specker B. Factors associated with physical activity in preschool children. J Pediatr. 2002;140:81-85. 
13. Pate RR, Mclver K, Dowda M, Brown WH, Addy C. Directly observed physical activity levels in preschool children. J Sch Health. 2008;78(8):438-444.

14. Ward DS. Physical activity in young children: The role of child care. Med Sci Sports Exerc. 2010;42:499501.

15. Hinkley T, Crawford D, Salmon J, Okely AD, Hesketh K. Preschool children and physical activity. Am J Prev Med. 2008;34:435-441.

16. Raustorp A, Pagels $P$, Boldemann C, Cosco N, Söderström M, Mårtensson F. Accelerometer measured level of physical activity indoors and outdoors during preschool time in Sweden and the United States. J Phys Act. 2012;9:801-808.

17. Cliff DP, Reilly JJ, Okely AD. Methodological considerations in using accelerometers to assess habitual physical activity in children aged 0-5 years. J Med Sci Sports. 2009;12:557-567.

18. Pate RR, O'Neill JR, Mitchell J. Measurement of physical activity in preschool children. Med Sci Sports Exerc. 2010;42:508-512.

19. Bornstein DB, Beets MW, Byun W, Mclver K. Accelerometer-derived physical activity levels of preschoolers: A meta-analysis. J Sci Med Sport. 2011;14:504-511.

20. Van Cauwenberghe E, Labarque V, Trost S, De Bourdeaudhuij I, Cardon G. Calibration and comparison of accelerometer cut points in preschool children. Int J Pediatr Obes. 2011;6:e582-e589.

21. Van Cauwenberghe E, Jones R, Hinkley T, Crawford D, Okely AD. Patterns of physical activity and sedentary behavior in preschool children. Int $\mathrm{J}$ Behav Nutr Phys Act. 2012;9:138. Available from: [http://www.ijbnpa.org/content/9/1/138] [Accessed November 20, 2013]

22. Verbestel V, Van Cauwenberghe E, De Coen V, Maes L, De Bourdeaudhuij I, Cardon G. Within- and between-day variability of objectively measured physical activity in pre-schoolers. Pediatr Exerc Sci. 2011;23:366-378.

23. Pate RR, Almeida AJ, Mclver KL, Pfeiffer KA, Dowda M. Validation and calibration of an accelerometer in preschool children. Obesity. 2006;14(11):2000-6.

24. Australian Government, Department of Health and Ageing. Physical activity recommendations for children 0-5 years. [http://www.health.gov.au/internet/main/publishing.nsf/content/health-pubhlth-strategphys-act-guidelines\#rec_0_5] Published 2010. [Accessed August 28, 2012]

25. Canadian Society for Exercise Physiology. Canadian physical activity guidelines and Canadian sedentary behavior guidelines. [http://www.csep.ca/CMFiles/Guidelines/CSEP-InfoSheets-early-yearsENG.pdf] Published 2012. [Accessed August 28, 2012]

26. Department of Health. UK physical activity guidelines. [http://www.dh.gov.uk/en/Publicationsandstatistics/Publications/PublicationsPolicyAndGuidance/DH_127 931] Published July 2011. [Accessed August 28, 2012]

27. Institute of Medicine (IOM). Early childhood obesity prevention: policies goals, recommendations, and potential actions. [http://www.iom.edu/Reports/2011/Early-Childhood-Obesity-PreventionPolicies/Recommendations.aspx] Published June 2011. [Accessed September 4, 2012]

28. Recommendations for Physical Activity in Early Childhood Education (2005). Handbooks of the Ministry of Social Affairs and Health 2005:17.

29. World Health Organization (WHO). Global recommendations on physical activity for health. 2010. Geneva. Switzerland.

30. Janssen X, Cliff DP, Reilly JJ et al. Predictive validity and classification accuracy of ActiGraph energy expenditure equations and cut-points in young children. Plos One. 2013;8(11):e79124. doi: 10.1371/journal.pone.0079124.

31. National Institute for Health and Welfare. Statistical report. [http://www.thl.fi/fi_Fl/web/fi/tilastot/aiheittain/lasten_sosiaalipalvelut/paivahoito] Published 2012. [Accessed June 13, 2013]

32. Weather Underground. Weather History \& Data Archive available at: [www.wunderground.com/history] [Accessed May 30, 2013]

33. Cardon G, De Bourdeaudhuij I. Are preschool children active enough? Objectively measured physical activity levels. Res Q Exerc Sport. 2008;79:326-332.

34. Fisher A, Reilly JJ, Montgomery $\mathrm{C}$ et al. Seasonality in physical activity and sedentary behavior in young children. Pediatr Exerc Sci. 2005;17:31-40.

35. Jackson DM, Reilly JJ, Kelly LA, Montgomery C, Grant S, Paton JY. Objectively measured physical activity in a representative sample of 3- to 4-year-old children. Obes Res. 2003;11:420-425.

36. Reilly JJ, Jackson DM, Montgomery C, et al. Total energy expenditure and physical activity in young Scottish children: mixed longitudinal study. Lancet. 2004;9494:211-212.

37. Pate RR, Pfeiffer KA, Trost SG, Ziegler P, Dowda M. Physical activity among children attending preschools. Pediatrics. 2004;114:1258-1263. 
38. Brown WH, Pfeiffer KA, Mclver KL, Dowda M, Addy CL, Pate RR. Social and environmental factors associated with preschoolers' nonsedentary physical activity. Child Dev. 2009;80:45-48.

39. Gubbels JS, Kremers SPJ, Van Kann DHH et al. Interaction between physical environment, social environment, and child characteristics in determining physical activity at child care. Health Psychol. 2011;30:84-90.

40. Cardon G, Van Cauwenberghe E, Labarque V, Haerens L, De Bourdeaudhuij I. The contribution of preschool playground factors in explaining children's physical activity during recess. Int J B Nutr Phys Act. 2008;5.

41. Boldeman $\mathrm{C}$, Blennow $\mathrm{M}$, Dal $\mathrm{H}$, et al. Impact of preschool environment upon children's physical activity and sun exposure. Prev Med. 2006;42:301-308.

42. Trost SG, Fees B, Dzewaltowski D. Feasibility and efficacy of a "move and learn" physical activity curriculum in preschool children. J Phys Act Health. 2008;5:88-103.

43. Matthews CE, Hagströmer M, Pober DM, Bowles HR. Best practices for using physical activity monitors in population-based research. Med Sci Sports Exerc. 2012;44: S68-S76. doi: 10.1249/MSS.0b013e3182399e5b. 